International Journal of Electrical and Power Engineering 5 (3): 150-156, 2011

ISSN: 1990-7958

(C) Medwell Journals, 2011

\title{
Three-Dimensional Electric Field Analysis and Measurement Inside High Voltage Substations
}

\author{
Sayed A. Word, Samy M. Ghania and Essam M. Shaalan \\ Department of Electrical Power, Faculty of Engineering, Benha University, Shoubra, Cairo, Egypt
}

\begin{abstract}
The exposure to electric field now-a-days is an integral part in the design area of electrical power apparatus and systems. Moreover, the electric field produced by power lines, busbars and all high voltage equipments inside High Voltage (HV) substations is receiving more and more concerns to guarantee the life insurance of workers inside these substations. Therefore, the possible effect of the electric field exposure raises the question of how electric fields are created and what effects they may have. Therefore, monitoring the electric field inside Air Insulated Substation (AIS) and Gas Insulated Substation (GIS) is achieved in this study. This study not only depict the electric field distribution inside AIS using Charge Simulation Method (CSM) in three Dimensional (3D) and many Matlab M-files modeling programs developed by the researchers but also measured it inside AIS under 500 and $220 \mathrm{kV}$ busbars and inside GIS nearby the 500,220 and $66 \mathrm{kV}$ busbars. The simulation results of AIS are compared with the measured values and the simulation results are matched with the measured values with very small tolerance about $1.4 \%$ for $220 \mathrm{kV}$ model and about $4.4 \%$ for $500 \mathrm{kV}$ model.
\end{abstract}

Key words: 3D electric field, AIS, GIS, charge simulation method, high voltage, Egypt

\section{INTRODUCTION}

Monitoring the $\mathrm{HV}$ electrical power equipments for electric fields have improved considerably in recent years. During the last years, electric and magnetic fields have been considered more and more as environmental factors. The International Commission on Non-Ionizing Radiation Protection (1998) published the guidelines. In these guidelines, the limit values for the electric field of $50 \mathrm{~Hz}$ are $5 \mathrm{kV} \mathrm{m}^{-1}$ for the public exposure (general public period of stay is $24 \mathrm{~h} \mathrm{day}^{-1}$ ) and $10 \mathrm{kV} \mathrm{m}{ }^{-1}$ for the occupational exposure (occupational period of stay is $8 \mathrm{~h} \mathrm{day}^{-1}$ ). In 2002, the IEEE standard was published in which the maximum permissible exposure for the public is $5 \mathrm{kV} \mathrm{m}^{-1}$ generally and $10 \mathrm{kV} \mathrm{m}^{-1}$ in power line right-of-way (IEEE Std., 2002).

In controlled environment, the maximum permissible exposure is $20 \mathrm{kV} \mathrm{m}^{-1}$ (Tzinevrakis et al., 2008). Therefore, the electric field calculation is one of the essential factors in the design and development of any electrical utilities. The electric field is usually calculated with the use of several numerical methods through a computer while the Charge simulation method is one of the numerical methods which are commonly used for engineering applications to compute successfully and accurately the electric field. Therefore, we use this method to simulate the electric field inside high voltage substations in three dimensional. In this thesis, we are going deeply to depict the electric field distribution inside HV electrical power substation while the electric field distribution under different voltage level busbars is simulated and measured inside these substations and the simulated results are compared with the measured values. Also, we are investigating the different parameters that control the electric field distribution inside HV substation by changing some of them as a case of study.

Substation description and system modeling: The selected $500 / 220 \mathrm{kV}$ AIS is supplied by four $500 \mathrm{kV}$ overhead transmission lines which are connected to the same main bus system. This substation has three identical 3-phase, $500 \mathrm{MVA}, 500 / 220 / 11 \mathrm{kV}$ power transformers installed inside it, each transformer is composed of three single phase transformers.

This substation has a simply 500 and $220 \mathrm{kV}$ bus systems with $300 \mathrm{~m}$ long and 12 and $9 \mathrm{~m}$ height, respectively. Detailed modeling procedure and mathematical model with respect to the technical data were presented in the research (Shaalan et al., 2010; Shaalan, 2011). Quick view on these substations layout and their models are presented in Fig. 1-3.

Electric field calculation methodology for the models under study: The basic principle of CSM lies in replacing

Corresponding Author: Sayed A. Word, Department of Electrical Power, Faculty of Engineering, Benha University, Shoubra, Cairo, Egypt 


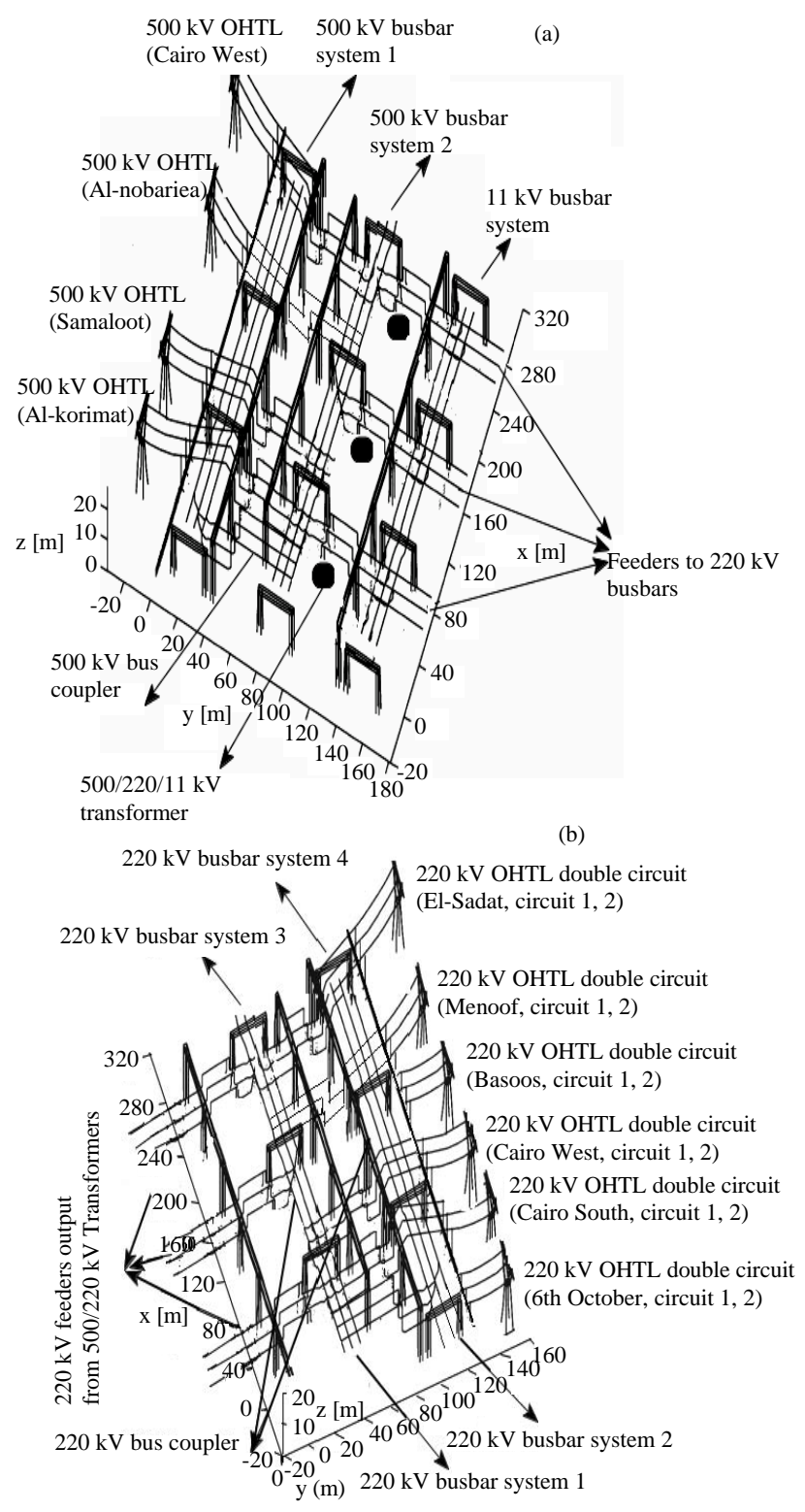

Fig. 1: 3D spatial model of 500 and $220 \mathrm{kV}$ switchyard inside AIS

the surface charge of the conductor with a set of discrete fictitious charges located inside the conductor. These fictitious charges generate the electric field of similar intensity and direction as the original conductors in the observed zone. For the present developed model, the fictitious linear charges are used for the modeling of the line conductors (phase conductors, main bus system and bypass system) with a certain arrangement (Shaalan et al., 2010; Shaalan, 2011).

Although, the type and position of these fictitious charges inside the conductors are specified in advance
(Shaalan et al., 2010; Shaalan, 2011), their values are unknown and in order to determine the value of these fictitious charges of the number $\left(n_{s}\right)$ on the conductor with known potential $\left(\mathrm{V}_{\text {con }}\right)$, a certain number $\left(\mathrm{n}_{\mathrm{cp}}\right)$ of contour points are selected where the condition $\left(n_{s}=n_{c p}\right)$ is satisfied. The contour points are placed at the conductor surface where the boundary conditions given by potentials of the contour points equal to $V_{\text {con }}$ are satisfied $\left(\mathrm{V}_{\mathrm{cp}}=\mathrm{V}_{\mathrm{con}}\right)$.

After choosing the type of fictitious charges as linear finite line type and distributing them along the simulated conductors. The values of these discrete charges are determined by satisfying the boundary conditions in Eq. 1 at a selected number of contour points where the potential of these fictitious charges are taken as particular solutions of Laplace equation which governs the assessment of the electric field:

Where:

$$
[\mathrm{V}]=[\mathrm{P}][\mathrm{Q}]
$$

$[\mathrm{Q}]=\mathrm{A}$ column vector of the fictitious simulation charges

$[\mathrm{V}]=\mathrm{A}$ column vector of the potential given by the boundary conditions

$[\mathrm{P}]=$ The matrix of the Maxwell potential coefficients (Kuffel et al., 2001; Malik, 1989)

Consider a finite line charge with constant charge densities (Total charge $Q_{j}$ ) of length (d) with both ends at $\left(\mathrm{X}_{1}-\mathrm{Z}_{1}\right)$ as end point and $(\mathrm{X}-\mathrm{Z})_{2}$ as starting point as shown in Fig. 4, then the potential coefficient $\left(\mathrm{P}_{\mathrm{ij}}\right)$ at any point $P_{i}(X-Z)$ due to this charge and its image charge $\left(Q_{j}\right)$ with respect to the plane is given as following:

$$
P_{i j}=\frac{1}{4 \pi \varepsilon d} \ln \left\{\frac{\left(L_{1}+L_{2}+d\right)\left(L_{11}+L_{22}-d\right)}{\left(L_{1}+L_{2}-d\right)\left(L_{11}+L_{22}+d\right)}\right\}
$$

Where:

$$
\begin{aligned}
& \mathrm{L}_{1}=\sqrt{\left(\mathrm{X}-\mathrm{X}_{1}\right)^{2}+\left(\mathrm{Y}-\mathrm{Y}_{1}\right)^{2}+\left(\mathrm{Z}-\mathrm{Z}_{1}\right)^{2}} \\
& \mathrm{~L}_{2}=\sqrt{\left(\mathrm{X}-\mathrm{X}_{2}\right)^{2}+\left(\mathrm{Y}-\mathrm{Y}_{2}\right)^{2}+\left(\mathrm{Z}-\mathrm{Z}_{2}\right)^{2}} \\
& \mathrm{~L}_{11}=\sqrt{\left(\mathrm{X}-\mathrm{X}_{1}\right)^{2}+\left(\mathrm{Y}-\mathrm{Y}_{1}\right)^{2}+\left(\mathrm{Z}+\mathrm{Z}_{1}\right)^{2}} \\
& \mathrm{~L}_{22}=\sqrt{\left(\mathrm{X}-\mathrm{X}_{2}\right)^{2}+\left(\mathrm{Y}-\mathrm{Y}_{2}\right)^{2}+\left(\mathrm{Z}+\mathrm{Z}_{2}\right)^{2}} \\
& \mathrm{~d}=\sqrt{\left(\mathrm{X}_{1}-\mathrm{X}_{2}\right)^{2}+\left(\mathrm{Y}_{1}-\mathrm{Y}_{2}\right)^{2}+\left(\mathrm{Z}_{1}-\mathrm{Z}_{2}\right)^{2}}
\end{aligned}
$$


Int. J. Elec. Power Eng., 5 (3): 150-156, 2011

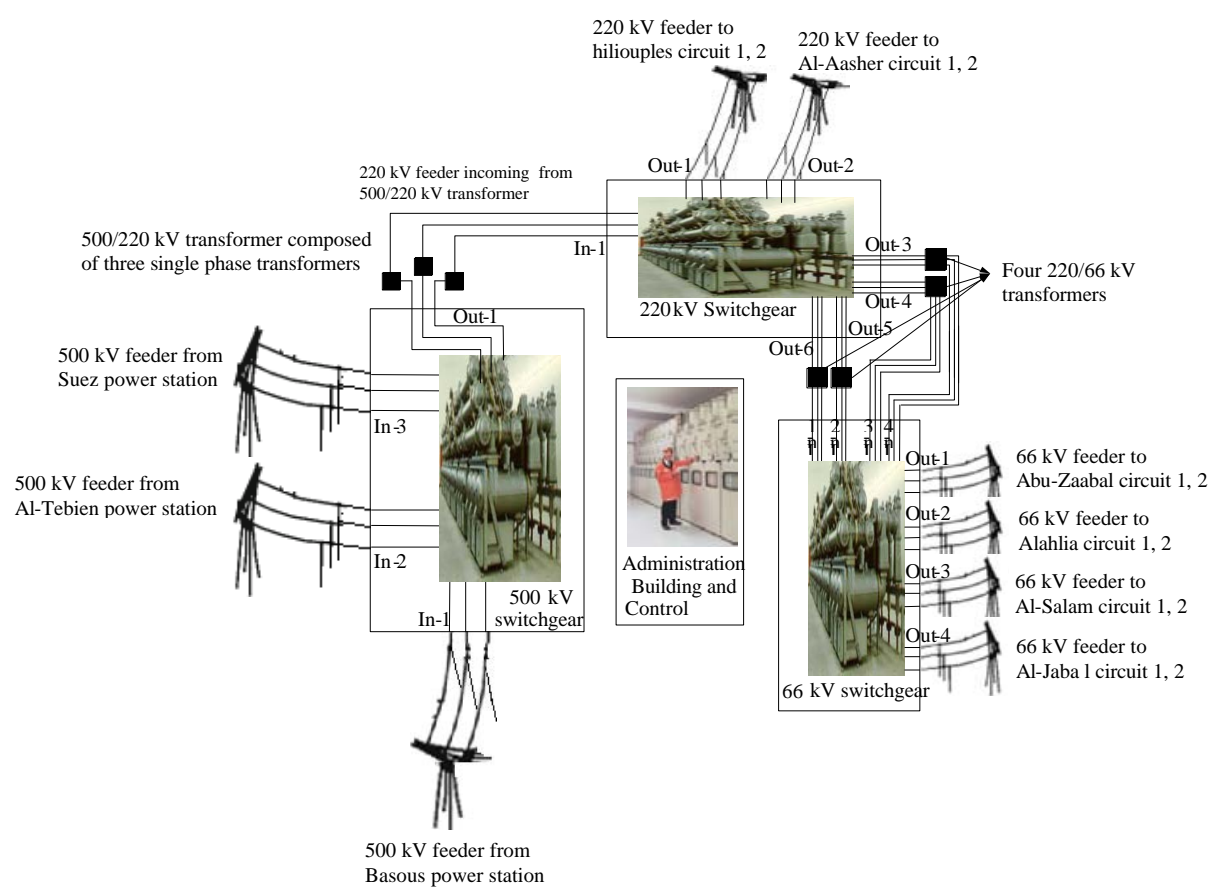

Fig. 2: Block diagram describing the analyzed GIS

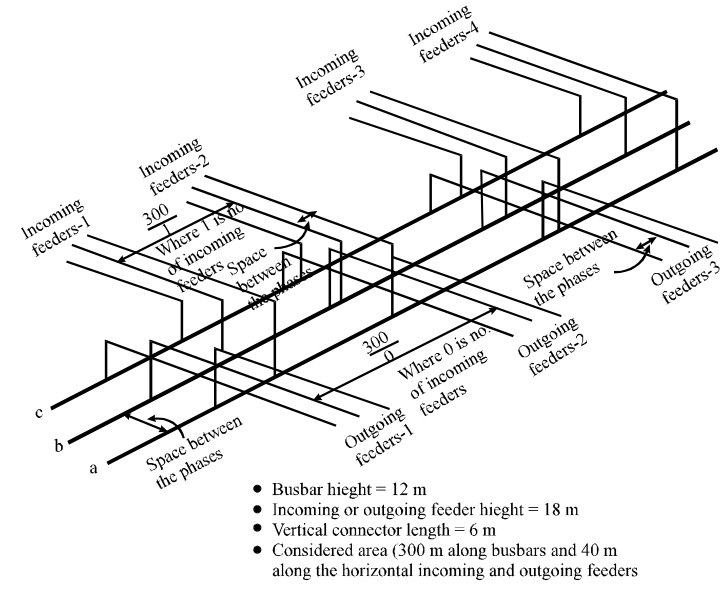

Fig. 3: The considered $500 \mathrm{kV}$ switchyard model of AIS to calculate the electric field inside it

After the calculation of the values of these charges then use the value of these charges to calculate the electric field strength produced by these fictitious charges. The expression for the Field coefficients (F) in the $x-z$ directions due to this finite line charge $\left(Q_{j}\right)$ and its image charge $\left(-\mathrm{Q}_{\mathrm{j}}\right)$ at any point $\left(\mathrm{P}_{\mathrm{i}}\right)$ are given as following:

$$
\mathrm{F}_{\mathrm{x}}=\frac{1}{4 \pi \varepsilon \mathrm{d}}\left\{\left(\frac{\mathrm{X}-\mathrm{X}_{1}}{\mathrm{~L}_{1}}+\frac{\mathrm{X}-\mathrm{X}_{2}}{\mathrm{~L}_{2}}\right) \Gamma 1-\left(\frac{\mathrm{X}-\mathrm{X}_{1}}{\mathrm{~L}_{11}}+\frac{\mathrm{X}-\mathrm{X}_{2}}{\mathrm{~L}_{22}}\right) \Gamma 2\right\}
$$

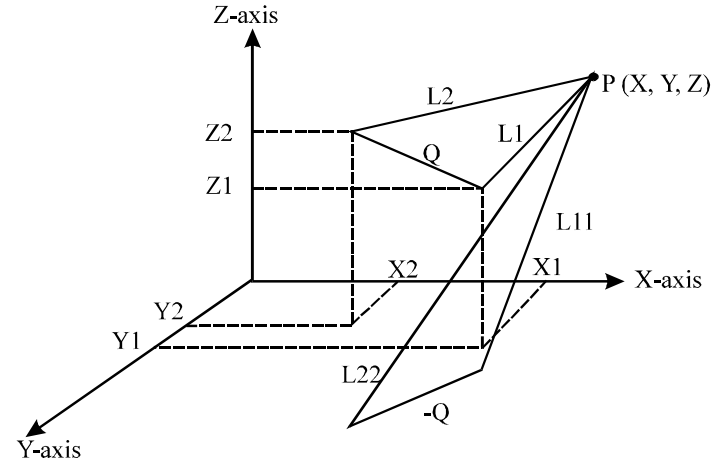

Fig. 4: Finite line charge with constant charge densities; total charge $Q_{j}$ and contour point $P_{i}$ in three dimensional; in $\mathrm{x}-\mathrm{z}$ directions

$$
\begin{gathered}
\mathrm{F}_{\mathrm{y}}=\frac{1}{4 \pi \varepsilon \mathrm{d}}\left\{\left(\frac{\mathrm{Y}-\mathrm{Y}_{1}}{\mathrm{~L}_{1}}+\frac{\mathrm{Y}-\mathrm{Y}_{2}}{\mathrm{~L}_{2}}\right) \Gamma 1-\left(\frac{\mathrm{Y}-\mathrm{Y}_{1}}{\mathrm{~L}_{11}}+\frac{\mathrm{Y}-\mathrm{Y}_{2}}{\mathrm{~L}_{22}}\right) \Gamma 2\right\} \\
\mathrm{F}_{\mathrm{z}}=\frac{1}{4 \pi \varepsilon \mathrm{d}}\left\{\left(\frac{\mathrm{Z}-\mathrm{Z}_{1}}{\mathrm{~L}_{1}}+\frac{\mathrm{Z}-\mathrm{Z}_{2}}{\mathrm{~L}_{2}}\right) \Gamma 1-\left(\frac{\mathrm{Z}+\mathrm{Z}_{1}}{\mathrm{~L}_{11}}+\frac{\mathrm{Z}+\mathrm{Z}_{2}}{\mathrm{~L}_{22}}\right) \Gamma 2\right\}
\end{gathered}
$$

Where:

$$
\begin{gathered}
\Gamma 1=\frac{1}{\left(L_{1}+L_{2}-d\right)}-\frac{1}{\left(L_{1}+L_{2}+d\right)} \\
\Gamma 2=\frac{1}{\left(L_{11}+L_{22}-d\right)}-\frac{1}{\left(L_{11}+L_{22}+d\right)}
\end{gathered}
$$


Therefore, the net field $\left(\underline{\mathrm{E}}_{\mathrm{i}}\right)$ at any point $\left(\mathrm{P}_{\mathrm{i}}\right)$ due to a number of individual charges ( $n$ ) each with charge of $Q_{j}$ is given as:

$$
\begin{aligned}
\underline{E}_{i} & =\left[\sum_{j=1}^{n}\left(F_{i j}\right)_{z}^{*} Q_{j}\right] \underline{a}_{x}+ \\
& {\left[\sum_{j=1}^{n}\left(F_{i j}\right)_{y}^{*} Q_{j}\right] \underline{a}_{y}+\left[\sum_{j=1}^{n}\left(F_{i j}\right)_{z}^{*} Q_{j}\right] \underline{a}_{z} }
\end{aligned}
$$

Where $\left(F_{i j}\right)_{z},\left(F_{i j}\right)_{y}$ and $\left(F_{i j}\right)_{z}$ are the field intensity or field coefficients and $\underline{\underline{a}}_{x}-\underline{a}_{z}$ are unit vectors in the $\mathrm{x}-\mathrm{Z}$ directions, respectively (Akazaki and Mishijima, 1978). We should be noted that after the calculation of the electric field produced by these fictitious charges, we should check the accuracy of the calculation of the electric field using the surface error.

But if it isn't meeting with the required accuracy of the calculation, you should change one of the following: the proper selection for the types of simulated charges (point, finite line, infinite line) and the suitable arrangement of these charges and contour points.

And then repeat these steps for many numbers of iteration till the accuracy of the calculation of the electric field using the surface error is meeting with the required accuracy of the calculation. Therefore, the calculation period of the simulation depends on the size of the boundary problems and the number of iterations till the required accuracy obtained. After the calculation of the electric field strength in a 3-phase system of sinusoidal low-frequency voltages, the root mean square values of the electric field strength are obtained which are proportional to the rms values of the voltages at all conductors. Finally, the CSM equations mentioned above are generalized in the form of many Matlab M-files programs with the same sequence to simulate and depict the electric field distribution inside the investigated substations.

\section{RESULTS AND DISCUSSION}

Steady state operation or normal operation: Within the $\mathrm{HV}$ investigated substations, the calculation of $3 \mathrm{D}$ electric field strength inside it and in its vicinity was performed in the 500 and $220 \mathrm{kV}$ switchyards area $(300 \mathrm{~m}$ along the bus length $\mathrm{x} 40 \mathrm{~m}$ around it; $20 \mathrm{~m}$ left and $20 \mathrm{~m}$ right) and the simulation results are shown as in Fig. 5 for $500 \mathrm{kV}$ switchyard and in Fig. 6 for $220 \mathrm{kV}$ switchyard. From Fig. 5 and 6 , outline the zones where the $10 \mathrm{kV} \mathrm{m}^{-1}$ professional exposure limit is exceeded, it is found that the highest values occurs under the $500 \mathrm{kV}$ busbars $\left(13.5 \mathrm{kV} \mathrm{m}^{-1}\right)$ under the connection conductors between $500 \mathrm{kV}$ busbars and power transformers. This is because of the circuit breakers and the disconnecting switches make the $500 \mathrm{kV}$ potential to go down to $6.5 \mathrm{~m}$ above the ground. On the $220 \mathrm{kV}$ side of the substation, there are quit small areas which under the circuit breakers and disconnecting switches (reclosers).

It should be noted that the above 3D calculations are performed when all incoming and outgoing feeders are turned on at spacing between the phases of $6 \mathrm{~m}$ for $500 \mathrm{kV}$ system and $4 \mathrm{~m}$ for $220 \mathrm{kV}$ system and at height level of calculation of $1 \mathrm{~m}$ (the base case of the study).

Changing the space between the phases: As shown in Table 1 and Fig. 7, we are noticed that the decreasing of the space between the phases will cause the maximum value of the calculated electric field strength is decreased because the cancellation factor is increased while the increasing of the spacing between the phases will
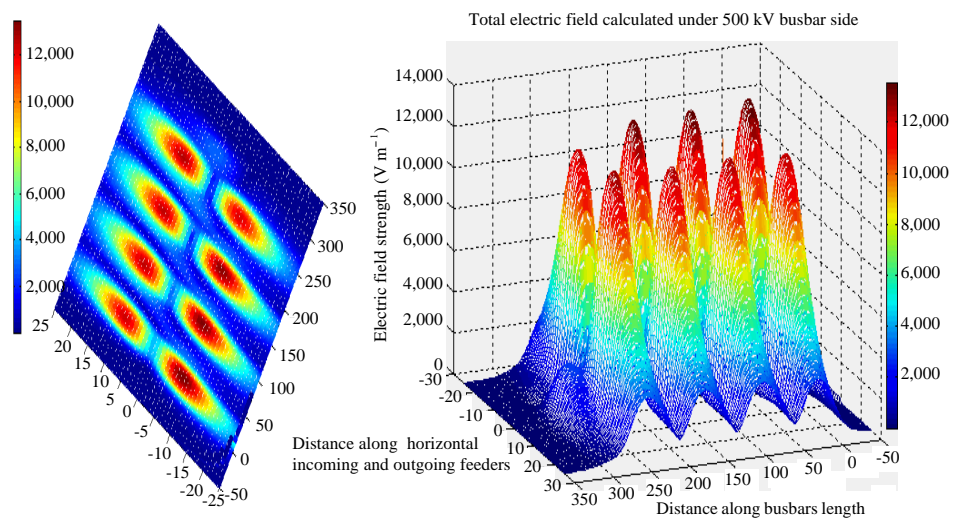

Fig. 5: The electric field distribution inside $500 \mathrm{kV}$ switchyard of AIS 
Int. J. Elec. Power Eng., 5 (3): 150-156, 2011

Table 1: The effect of changing the space between the phases on the calculated electric field

\begin{tabular}{lccccll}
\hline $\begin{array}{l}\text { The operating } \\
\text { voltage }\end{array}$ & $\begin{array}{c}\text { The height } \\
\text { level of } \\
\text { calculation }\end{array}$ & $\begin{array}{c}\text { The spacing } \\
\text { between the } \\
\text { phases }(\mathrm{m})\end{array}$ & $\begin{array}{c}\text { Maximum } \\
\text { field value } \\
\left(\mathrm{kV} \mathrm{m}^{-1}\right)\end{array}$ & $\begin{array}{c}\text { Average } \\
\text { field value } \\
\left(\mathrm{kV} \mathrm{m}^{-1}\right)\end{array}$ & $\begin{array}{l}\text { Position of } \\
\text { maximum field } \\
(\mathrm{x}, \mathrm{y})(\mathrm{m})\end{array}$ & Comment \\
\hline $500 \mathrm{kV}$ & $1 \mathrm{~m}$ & 6 & 13.45 & 4.91 & $\mathrm{P}(\mathrm{x}, \mathrm{y})=\mathrm{P}(19,21)$ & Base case \\
& & 5 & 12.26 & 4.32 & $\mathrm{P}(\mathrm{x}, \mathrm{y})=\mathrm{P}(56,22)$ & Field intensity decreased with $8.83 \%$ from base case \\
& & 4 & 11.84 & 3.85 & $\mathrm{P}(\mathrm{x}, \mathrm{y})=\mathrm{P}(56,22)$ & Field intensity decreased with $11.95 \%$ from base case \\
& 7 & 14.53 & 5.46 & $\mathrm{P}(\mathrm{x}, \mathrm{y})=\mathrm{P}(19,21)$ & Field intensity increased with $8.04 \%$ from base case \\
& 8 & 14.64 & 5.47 & $\mathrm{P}(\mathrm{x}, \mathrm{y})=\mathrm{P}(19,21)$ & Field intensity increased with $8.85 \%$ from base case \\
\hline
\end{tabular}

Table 2: The effect of changing the height level of calculation on the calculated electric field

\begin{tabular}{lccccll}
$\begin{array}{l}\text { The operating } \\
\text { voltage }\end{array}$ & $\begin{array}{c}\text { The spacing } \\
\text { between } \\
\text { the phases }\end{array}$ & $\begin{array}{c}\text { The height } \\
\text { level of } \\
\text { Calculation }(\mathrm{m})\end{array}$ & $\begin{array}{c}\text { Maximum } \\
\text { field value } \\
\left(\mathrm{kV} \mathrm{m}^{-1}\right)\end{array}$ & $\begin{array}{c}\text { Average } \\
\text { field value } \\
\left(\mathrm{kV} \mathrm{m}^{-1}\right)\end{array}$ & $\begin{array}{l}\text { Position of } \\
\text { maximum field } \\
(\mathrm{x}, \mathrm{y})(\mathrm{m})\end{array}$ & Comment \\
\hline $500 \mathrm{kV}$ & $6 \mathrm{~m}$ & 1 & 13.45 & 4.910 & $\mathrm{P}(\mathrm{x}, \mathrm{y})=\mathrm{P}(19,21)$ & Base case \\
& 2 & 13.95 & 5.055 & $\mathrm{P}(\mathrm{x}, \mathrm{y})=\mathrm{P}(19,21)$ & Field intensity increased with 3.69\% from base case \\
& 3 & 14.83 & 5.388 & $\mathrm{P}(\mathrm{x}, \mathrm{y})=\mathrm{P}(19,22)$ & Field intensity increased with 10.24\% from base case \\
\hline
\end{tabular}

\begin{tabular}{lccll} 
Table 3: The effect of switching on/off one or more feeders on the calculated electric field \\
The condition & $\begin{array}{c}\text { Maximum } \\
\text { field value } \\
\left(\mathrm{kV} \mathrm{m}^{-1}\right)\end{array}$ & $\begin{array}{c}\text { Average } \\
\text { field value } \\
\left(\mathrm{kV} \mathrm{m}^{-1}\right)\end{array}$ & $\begin{array}{l}\text { Position of } \\
\text { maximum field } \\
(\mathrm{x}, \mathrm{y})(\mathrm{m})\end{array}$ & $\begin{array}{l}\text { Percent difference } \\
\text { with respect } \\
\text { to the base case }\end{array}$ \\
Normal operation & 13.45 & 4.91 & $\mathrm{P}(\mathrm{x}, \mathrm{y})=(19,21)$ & Base case \\
Middle incoming feeder is switched off & 13.95 & 4.99 & $\mathrm{P}(\mathrm{x}, \mathrm{y})=(56,21)$ & Field strength increased with $3.72 \%$ from base case \\
Two sides incoming feeders are switched off & 14.07 & 5.05 & $\mathrm{P}(\mathrm{x}, \mathrm{y})=(37,21)$ & Field strength increased with 4.57\% from base case \\
Middle outgoing feeder is switched off & 13.93 & 5.13 & $\mathrm{P}(\mathrm{x}, \mathrm{y})=(74,30)$ & Field strength increased with 3.51\% from base case \\
Two sides outgoing feeders are switched off & 15.22 & 5.29 & $\mathrm{P}(\mathrm{x}, \mathrm{y})=(74,29)$ & Field strength increased with 13.13\% from base case \\
\hline
\end{tabular}

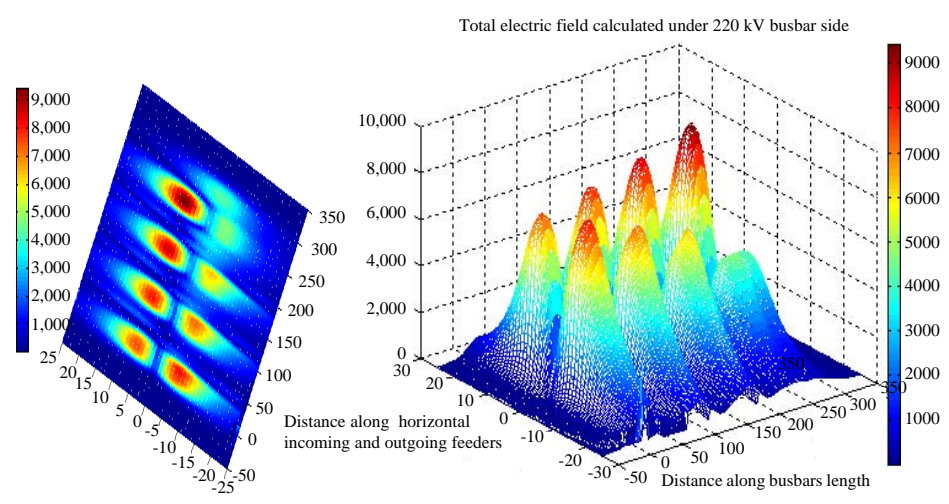

Fig. 6: The electric field distribution inside $220 \mathrm{kV}$ switchyard of AIS; a) base case at space of $6 \mathrm{~m}$, bus height of $12 \mathrm{~m}$; b) at space of $6.2 \mathrm{~m}$ and c) at space of $5.8 \mathrm{~m}$

increase the maximum value of the calculated electric field strength because of the decreasing of the cancellation factor. But we should be noted that while decreasing the space between the phases, it should keep the insulation between the phases with stated values by national standards for each operating voltage to prevent the breakdown occurrence.

Changing the height level of calculation: From Fig. 8 and Table 2, we are noticed that as the height level of calculation is increased, the maximum value of the calculated field strength is increased because of closing from the live parts.

This meaning also that as the height level for supporting the live conductors (busbars, incoming feeders and outgoing feeders) increased, the maximum value of the calculated field strength is decreased because of the distance from the live parts.

Changing the load condition: From the given Table 3 , we can note that as the middle incoming feeder is switched off the maximum electric field value is increased by $3.72 \%$ from base case; this is due to the reduction in the contribution of this feeder in the field cancellation factor. Besides that when all outgoing feeders are put off the maximum electric field value is increased by $24.75 \%$ from base case, this because the contribution of cancellation factor from all these lines are stopped and consequently a higher electric field value is obtained. 

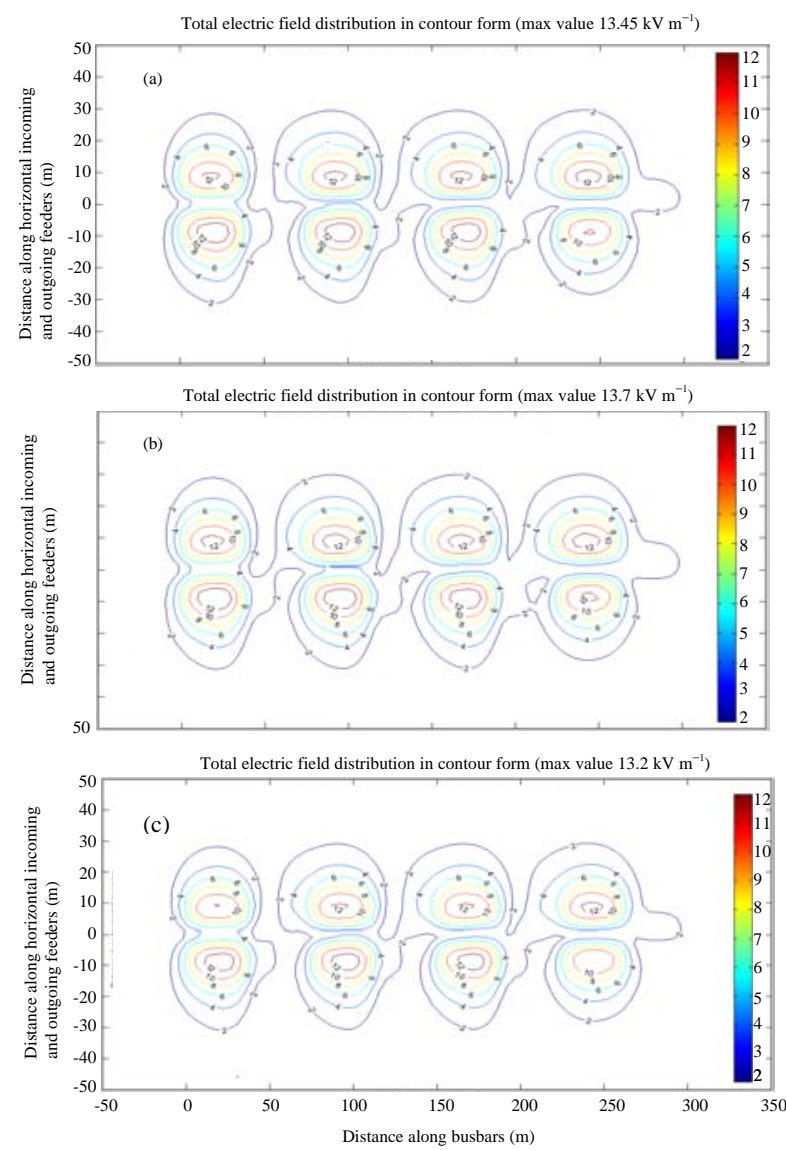

Fig. 7: The electric field distribution due to changing the space between the phases; a) at bus height of $12.2 \mathrm{~m}$ and $\mathrm{b}$ ) at bus height of $11.8 \mathrm{~m}$
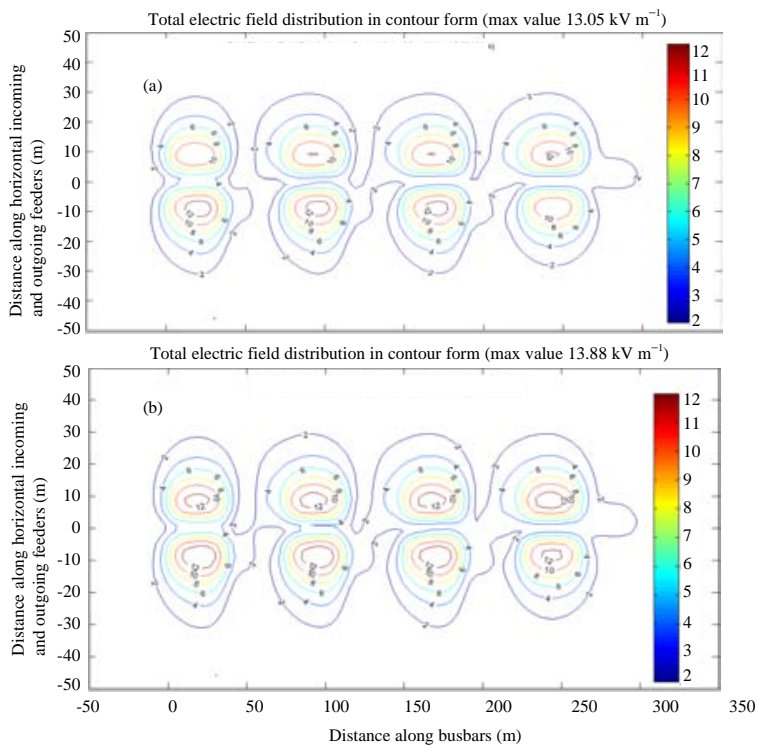

Fig. 8: The electric field distribution due to changing the height level of supporting the conductors
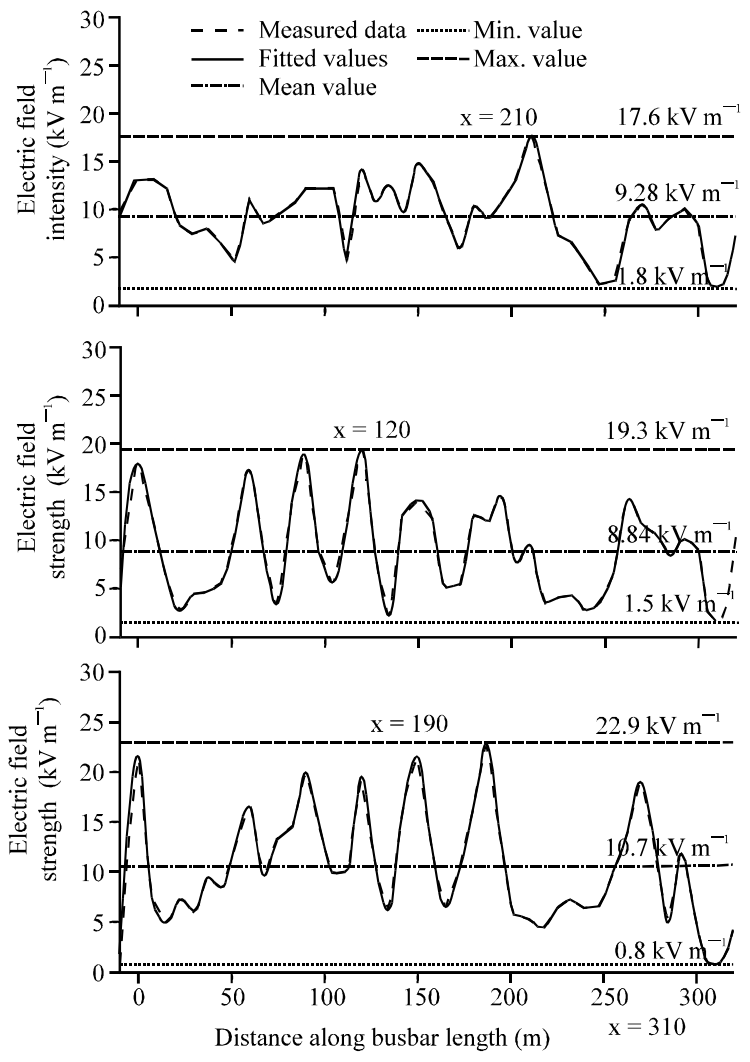

Fig. 9: The longitudinal electric field profiles measured under $500 \mathrm{kV}$ (phase A-C)switchyard inside cairo 500 substation at level $1 \mathrm{~m}$

The measurement of the electric field inside $\mathrm{HV}$ substations: The electric field measurements are performed in this study at $1 \mathrm{~m}$ above the ground surface and underneath the 500 and $220 \mathrm{kV}$ switchyards of AIS beside its measurement inside GIS nearby the 500,220 and $66 \mathrm{kV}$ busbars with $0.5 \mathrm{~m}$. The measurement of electric field is performed using an advanced field meter; $\mathrm{HI} 3604$ ELF survey meter (Holaday Industries, 2002). Outlines the longitudinal electric field profiles measured under different phases of $500 \mathrm{kV}$ switchyard inside the substation as shown in Fig. 9. From Fig. 9, it is noticed that the maximum electric field value due to the different 3-phases is $22.9 \mathrm{kV} \mathrm{m}^{-1}$ and occurs at position $\mathrm{x}=190 \mathrm{~m}$ along the busbar length and located under phase $\mathrm{C}$ of $500 \mathrm{kV}$ busbar. Therefore, we can note that the electric field measured values are decreased as nearby from the $500 \mathrm{kV}$ switchgear due to the increasing of the field cancellation factor. The maximum calculated value of electric field strength is $23.9 \mathrm{kV} \mathrm{m}^{-1}$ while the maximum measured value is $22.9 \mathrm{kV} \mathrm{m} \mathrm{m}^{-1}$, therefore the simulation results are matched with the measured values with very small tolerance (about 4.4\%) which is due to the field meter 
used in the measurements is dependent on the natural of place where the electric field is measured. Also, the measured values inside GIS showed that the value of the electric field does not exceed the maximum permissible limit while its value not exceeds $2 \mathrm{~V} \mathrm{~m}^{-1}$ inside insulated switchgear rooms.

\section{CONCLUSION}

Following the electric field distribution inside AIS, there are large areas especially in the $500 \mathrm{kV}$ switchyard where the electric field intensity is $>10 \mathrm{kV} \mathrm{m}^{-1}$; exceeds the professional exposure limit and when following the electric field distribution inside GIS, it is found that the electric field intensity is very quit small and not exceeds the professional exposure limit inside the switchgear rooms but the highest values have been found in the neighborhood of the incoming $500 \mathrm{kV}$ transmission lines which are not encapsulated inside enclosures filled with $\mathrm{SF}_{6}$ where the electric field strength under these lines reaches values up to $22.5 \mathrm{kV} \mathrm{m}^{-1}$; exceeds the professional exposure limit. The calculated and measured electric field around the fence of the substation is separated into three areas. In area $\mathrm{I}$, the field is $<5 \mathrm{kV} \mathrm{m}^{-1}$, area III has $<10 \mathrm{kV} \mathrm{m}^{-1}$. The maximum is in the area II under the $500 \mathrm{kV}$ transmission lines which is greater than the limit for $24 \mathrm{~h}$ exposure time for humans. Therefore, the results presented show that the professional human exposure limit to the electric field is significantly exceeded in several areas of AIS especially under the $500 \mathrm{kV}$ lines, busbars and around the power transformers.

\section{RECOMMENDATIONS}

Therefore, the electric field strength can be decreased to meet the national standards reference exposure levels by one from the following:

- Increasing the height level of busbars, incoming feeders and outgoing feeders (live conductors) for example, particularly in $500 \mathrm{kV}$ substations with proposed $12 \mathrm{~m}$ busbar height. If the ICNIRP levels are not met, the busbar height has to be increased to $14 \mathrm{~m}$ with significant cost implications
- Decreasing the space between the phases of busbars, incoming feeders and outgoing feeders (live conductors) but with a limit value to insure the insulation between them and prevent the occurrence of breakdown

- The live conductors (busbars, incoming feeders and outgoing feeders shall be housed in separate metal enclosed modules called metal-clad switchgear which filled with a superior dielectric gas; sulfur hexafluoride $\left(\mathrm{SF}_{6}\right)$

\section{REFERENCES}

Akazaki, M. and K. Mishijima, 1978. Calculation of three dimensional axisymmetric fields by charge simulation method. Electr. Eng. Jap., 98: 1-7.

Holaday Industries, 2002. HI 3604 ELF survey meter user's manual. Holaday Industries Inc., USA.

IEEE Std., 2002. Safety levels with respect to human exposure to electromagnetic fields, $0-3 \mathrm{kHz}$. IEEE Std. C95.6-2002, Oct. 2002. http://ieeexplore.ieee.org/xpl/ freeabs_all.jsp?arnumber $=1046043$.

International Commission on Non-Ionizing Radiation Protection, 1998. Guidelines for limiting exposure to time-varying electric, magnetic and electromagnetic fields (up to $300 \mathrm{GHz}$ ). International commission on non-ionizing radiation protection. Health Phys., 74: 494-522.

Kuffel, E., W.S. Zaengle and J. Kuffel, 2001. High Voltage Engineering, Fundamentals. 2nd Edn., Newnes, New York.

Malik, N.H., 1989. A review of the charge simulation method and its applications. IEEE Trans. Electr. Insul., 24: 3-20.

Shaalan, E.M., S.M. Ghania and S.A. Ward, 2010. Analysis of electric field inside hv substations using charge simulation method in three dimensional. Annual Report Conference on Electrical Insulation and Dielectric Phenomena (CEIDP), October 2010.

Shaalan, E.M., 2011. Electric field calculation inside GIS using CSM in 3D. M.Sc. Thesis, Faculty of Engineering at Shoubra, Benha University, Egypt.

Tzinevrakis, A.E., D.K. Tsanakas and E.I. Mimos, 2008. Analytical calculation of the electric field produced by single-circuit power lines. IEEE Trans. Power Delivery, 23: 1495-1505. 